\title{
Reflexões sobre o uso do facebook e as redes sociométricas do psicodrama
}

\author{
Reflections on the use of facebook and the psychodrama sociometric networks
}

Elizabele Maria Sobrinho ${ }^{[a]}$, Maria Cristina Antunes ${ }^{[b]}$

\footnotetext{
${ }^{[a]}$ Psicóloga Clínica, mestre em Psicologia Social Comunitária (UTP), especialista em Administração de Pessoas (UFPR), psicóloga Perita Examinadora de Trânsito (PUC-PR) e docente da Graduação em Psicologia (FACEL), Curitiba, PR - Brasil, e-mail: elizabele.sobrinho@hotmail.com

${ }^{[b]}$ Psicóloga Clínica, mestre em Psicologia Social, doutora em Psicologia Social (USP), psicodramatista pelo Instituto J.L.Moreno de SP e Zerca Moreno Workshops - USA e docente do Mestrado em Psicologia (UTP), Curitiba, PR - Brasil, e-mail: mcrisantunes@uol.com.br
}

Recebido: 01/07/2013 Received: 07/01/2013

Aprovado: $26 / 08 / 2013$ Approved: 08/26/2013

\section{Resumo}

Este estudo tem o objetivo de analisar o ciberespaço como um fenômeno social, verificando possíveis interlocuções entre o uso da rede social Facebook com as Redes Sociométricas do Psicodrama. No século XXI, as relações mediadas pelo computador ganham cada vez mais adeptos e a maior parte dessa navegação é feita em plataformas de redes sociais, sendo o Facebook, o site mais utilizado atualmente pelos brasileiros. Esta modalidade de relacionamento virtual mudou significativamente a forma como as pessoas se relacionam e interagem. Para o psicodrama, toda relação interpessoal acontece por intermédio dos papéis, que influenciam o ambiente e a cultura. As comunidades virtuais são permeadas por interesses comuns, afinidades, paixões e conflitos, tal como as redes sociométricas. Nas redes virtuais, as pessoas podem fazer suas escolhas de amizades a partir de três modos, conforme a teoria psicodramática: atração (afinidade), rejeição (distância) e neutralidade. As redes sociométricas configuram-se a partir dos entrelaçamentos dos vínculos e são compostas por diversos átomos sociais, formando uma rede de sociabilidades. As redes virtuais são uma expressão das redes sociométricas, e a maneira como a pessoa utiliza este dispositivo tecnológico e estabelece as suas relações no ambiente virtual terá um impacto no seu capital social.

Palavras-chave: Facebook. Redes sociométricas. Comunidade virtual.

\begin{abstract}
The objective of this study is to analyze the cyberspace as a social phenomenon, and to check the possible links among the use of Facebook and Psychodrama's Sociometric Networks. In the 21st century, relations are being mediated by the computer, which has been gaining more users. A greater part of this web navigation happens in social network platforms, and Facebook has been the most commonly used website by Brazilians. This modality of virtual relationship changed significantly interactions and relationships of people. Psychodrama says that all interpersonal relationships happen through roles, and they influence the culture and the environment. Virtual communities are permeated by common interests, affinities, passions, and conflicts, as well as sociometric networks. According to Psychodrama, people can choose their friendships in virtual networks by attraction (affinity), rejection (detachment), and neutrality. Sociometric networks are
\end{abstract}

Psicol. Argum. 2014, 32(79), Supl. 2, 99-109 
set up from intertwined relationships, and they are composed by several social atoms that make a sociability network. Virtual networks are an expression of sociometric networks, and there is an impact in social capital because of the use of the way the user uses this technology.

Keywords: Facebook. Sociometric networks. Online community.

\section{Introduç̃o}

Este artigo pretende discutir a rede social de relacionamento Facebook de acordo com os conceitos de redes da psicologia comunitária e de redes sociométricas do psicodrama. Será realizada uma descrição do dispositivo tecnológico Facebook e dos conceitos de matriz de identidade, átomo social, átomo cultural, papéis, tele e redes sociométricas. Em seguida, serão discutidas as redes comunitárias na perspectiva da psicologia social comunitária, comunidades virtuais, ciberespaço, cibercultura e capital social. 0 objetivo deste texto não é contemplar a questão em toda a sua complexidade, mas levantar algumas discussões e reflexões sobre esta nova forma de relacionamento virtual que vêm se configurando na contemporaneidade. O Facebook, segundo Kirkpatrick (2011), é o segundo site mais visitado do mundo, e já opera em 75 idiomas. Trata-se de uma nova forma de comunicação que dá prioridade as pessoas. "É uma plataforma para que elas obtenham mais da própria vida" (p. 25).

Conforme o Socialbakers Heart of Facebook Statistics (2013), o Facebook em janeiro de 2013 possuía 981.438.160 usuários no mundo, sendo 143.047.640 na América do Sul, 65.301.560 usuários especificamente no Brasil. Nas principais capitais do Brasil, os números estão distribuídos da seguinte maneira: São Paulo com 8.791.700 usuários, Rio de Janeiro com 5.062.320, Curitiba com 1.272.480 e Goiânia 814.920. Quanto à distribuição por sexo no Brasil, 54\% são mulheres e $46 \%$ homens. Quanto à idade, $32 \%$ estão entre 18 24 anos, 28\% entre 25-34 anos, 14\% entre 35-44 anos, 8\% entre $45-54$ anos, $7 \%$ entre $16-17$ anos, 7\% entre 13-15 anos, 3\% entre 55-64 e 1\% acima de 65 anos. Essa nova prática, que mudou significativamente a forma como as pessoas se relacionam, aponta a relevância de reflexões sobre esta temática.

\section{Facebook}

De acordo com Recuero (2010), o site de relacionamentos Facebook (originalmente thefacebook), foi criado no ano de 2004 por Mark Zuckerberg, estudante da universidade de Harvard. Conforme descreve Fonseca (2010), inicialmente a plataforma estava disponível apenas para estudantes da própria universidade, expandindo-se mais tarde para outras universidades americanas. Em 2005, com a empresa Facebook já constituída, foi possível disponibilizar o uso da rede ao público geral, estando hoje ao alcance de qualquer pessoa com acesso à internet. 0 Facebook é uma plataforma de comunicação online caracterizada pela mídia como rede social, que tem como objetivo promover o contato entre os atores sociais nela inseridas. Por intermédio desse site, os atores podem trocar mensagens com objetivos variados. 0 dispositivo tecnológico é caracterizado por uma multiplicidade de possibilidades de interação, que podem ser lúdicas, profissionais, políticas e de cidadania.

A seguir são descritos brevemente os principais recursos de interação que a plataforma oferece (Facebook, 2012):

- Mural: é um espaço no perfil do usuário em que ele e os amigos podem publicar e compartilhar informações;

- Feed de notícias: é a lista contínua de atualizações na página inicial que mostra as novidades dos amigos e das páginas que a pessoa segue;

- Mensagens: é um lugar central para trocar mensagens privadas, conversas, $e$-mails e mensagens de texto;

- Bate-papo é um recurso que permite enviar mensagens instantâneas para amigos on-line;

- Chamada de vídeo: permite conversar com os amigos diretamente com a possibilidade de visualização (cara a cara); 
- Assinar: é uma maneira para obter novidades de pessoas pelas quais o usuário se interessa, mesmo que não sejam amigos, como jornalistas, celebridades, figuras políticas, entre outros;

- Curtir: para curtir o conteúdo que os amigos publicam, curtir uma página com a qual o usuário quer estar conectado, ou ainda se conectar ao conteúdo de páginas por meio de plug-ins sociais (ferramentas que outros sites podem usar para proporcionar experiências personalizadas e sociais às pessoas) e anúncios dentro e fora do Facebook;

- Cutucar: é uma forma de chamar a atenção de outro usuário que não necessariamente esteja na lista de amigos. Ao cutucar alguém, a outra pessoa recebe um alerta em sua página inicial;

- Jogos e aplicativos: o usuário pode fazer uso de jogos e adicionar aplicativos ao seu perfil (eventos, fotos, compartilhar o que se está lendo, ouvir músicas com os amigos etc.);

- Vídeo: possibilidade de carregar vídeos curtos para compartilhar experiências com os amigos;

- Fotos: permite ao usuário compartilhar imagens e marcar pessoas nelas;

- Locais: o usuário pode compartilhar a sua localização com os amigos ao visitar locais e com este recurso também pode encontrar amigos nas proximidades;

- Evento: é um recurso que permite organizar reuniões e manter-se atualizado sobre o que os amigos estão fazendo;

- Telefone celular: é possível se cadastrar e utilizar o Facebook por dispositivos móveis;

- Grupo: são círculos fechados para manter contato e compartilhar interesses comuns.

Para Kirkpatrick (2011):

O Facebook está unindo o mundo. Tornou-se uma abrangente experiência cultural partilhada por pessoas em todo o planeta, especialmente jovens. Apesar de seu início modesto como um projeto de faculdade de um rapaz de 19 anos de idade, tornou-se uma potência tecnológica com influência sem precedentes sobre toda a vida moderna, tanto pública quanto privada. Sua composição inclui as mais diversas gerações, geografias, idiomas e classes sociais. Talvez seja, na realidade, a empresa de mais rápido crescimento em toda história. [...] Ele muda a forma como as pessoas se comunicam e interagem, como os comerciantes vendem seus produtos, como os governos chegam aos cidadãos e até como as pessoas operam. Está alterando a natureza do ativismo político e, em alguns países, está começando afetar o processo da própria democracia. Já não é apenas um brinquedo para estudantes universitários (p. 24).

Miller (2011), em um livro intitulado Tales from Facebook, relata a história de 12 pessoas que fazem uso do Facebook na Ilha de Trinidad no Caribe. Em sua pesquisa fica evidente que o Facebook está revitalizando e expandindo as comunidades. 0 autor escolheu essa região por ser um local de grande diversidade étnica e cultural e diferente dos lugares comumente pesquisados, como Estados Unidos e Europa. Os participantes da pesquisa não fazem distinção entre a comunidade off-line e o Facebook, referindo-se a ambas como comunidade. 0 dispositivo tecnológico é relatado como uma ferramenta que facilita o contato com as pessoas distantes ou com quem se havia perdido contato, possibilitando interação com um grande número de pessoas. Uma das entrevistadas, Alana, jovem universitária de 25 anos, nascida e criada em uma pequena vila, comunidade real onde todos conhecem todos, reconhece o Facebook como semelhante em tudo à sua pequena vila no aspecto comunidade. Para a entrevistada não há qualquer evidência de que as pessoas passem menos tempo juntas como resultado do uso do site. Ao contrário, o espaço virtual é utilizado para organizar e coordenar eventos off-line, como reuniões familiares e discussão de trabalhos escolares. Os entrevistados também fazem referências a questões do trânsito e violência como fatores que fazem com que as pessoas não queiram sair de suas residências e em que o Facebook viabiliza o contato. Conforme o autor, o site de relacionamento ajuda quando as pessoas têm dificuldades em se reunirem pessoalmente, e acrescenta: "O Facebook funciona melhor quando usado para compensar as deficiências ou as situações estressantes de outras formas de comunicação. Esta pode ser encarada como uma das principais conclusões do estudo desse livro" ( $p$. 184, tradução nossa).

Fonseca (2010) fez um mapeamento das interações que são realizadas no Facebook, utilizando-se de metodologia qualitativa, com entrevistas semidirigidas a 8 participantes, com idades entre 18 e 25

Psicol. Argum. 2014, 32(79), Supl. 2, 99-109 
anos, sendo 4 mulheres e 4 homens em Portugal. 0 autor, ao falar das amizades virtuais, relata que:

O conceito de amizade no Facebook não acarreta o mesmo significado de amizade off-line, sendo que ser amigo neste sítio é sinônimo de ter uma rede de contatos. Esta rede engloba os 'amigos' off-line, os conhecidos, os amigos dos amigos e os novos amigos criados através do Facebook (p. 2).

\section{Átomo social, átomo cultural, papéis e redes sociométricas}

Segundo Gonçalves, Wolf e Almeida (1988), para investigar e compreender a inter-relação entre as pessoas, as leis que regem o comportamento social e grupal, Moreno (1959), criou a socionomia, que se divide em três vertentes: a sociodinâmica, que estuda a dinâmica dos grupos, a sociometria, que mensura as relações entre as pessoas e a sociatria, que é a terapêutica das relações sociais.

Para que possamos entender como se formam as redes sociométricas, vamos falar sobre a formação da identidade que se inicia na relação da criança com as pessoas de maior proximidade afetiva, passando pela formação e internalização de papéis; abordaremos o átomo social, ou seja, as relações interpessoais que se desenvolvem a partir do nascimento e dependem do fator tele (responsável pela coesão grupal), até chegarmos ao átomo cultural (conjunto das relações entre papéis). Por meio da identificação com as culturas vigentes das redes se formam as redes sociométricas.

Para Moreno, conforme Gonçalves et al. (1988), a criança ao nascer é inserida em um conjunto de relações, tendo como seu primeiro ego-auxiliar a sua mãe, e posteriormente, seu pai, irmãos, avós, tios entre outros; denominando este conjunto de relações de Matriz de Identidade. Dentro desta concepção, o indivíduo é, então, um ser social, porque nasce em sociedade, constitui-se nas relações interpessoais, necessita dos outros para sobreviver e está apto a se relacionar e conviver com outras pessoas.

De acordo com Moreno (2008), "é possível identificar, na fronteira entre o indivíduo e o grupo, um conjunto de atrações, repulsões e indiferenças. Esse padrão é chamado de átomo social, ou seja, a menor unidade funcional dentro de um grupo social" (p. 88). Desde o nascimento, a pessoa está em contato com uma estrutura de relações ao seu redor, porém, com o passar do tempo, o átomo social vai se expandindo e novas pessoas vão surgindo na vida do indivíduo. 0 autor descreve também o que chama de átomo cultural: "a menor unidade funcional dentro de um padrão cultural" (p. 89), ou seja, considera os papéis e as relações entre eles como o desenvolvimento mais significativo dentro de uma cultura. Nessa perspectiva, átomo social e cultural acabam sendo manifestações da mesma realidade social.

Para a teoria psicodramática, toda relação ocorre por intermédio dos papéis. Moreno (1999) define papel como: "a menor unidade de uma cultura" (p. 50). Os papéis e as relações que acontecem por meio desses papéis são os fenômenos mais importantes de uma determinada cultura. Esses papéis não aparecem de forma isolada, mas sim conglomerados, ou seja, a pessoa desempenha vários papéis ao mesmo tempo, modificando o ambiente e a cultura ao qual está inserido.

Segundo Fonseca Filho (1980), o desempenho do papel é anterior ao surgimento da linguagem e do ego. "Um papel é uma experiência interpessoal e necessita de dois ou mais indivíduos para ser posto em ação. Todo papel é uma resposta a outro (de outra pessoa). Não existe papel sem contra-papel" (p. 20).

Moreno (2008) utiliza o termo tele "para expressar a mais simples unidade de sentimento transmitida de um indivíduo a outro" (p. 248). 0 fator tele deve ser compreendido como um processo dentro do átomo social, que é responsável pela coesão grupal, tornando as relações mais sadias.

De acordo com Menegazzo, Tomasin e Zuretti (1995):

O fenômeno tele manifesta-se na vincularidade grupal como energia de atração, rejeição e indiferença, e evidencia uma permanente atividade de comunicação co-inconsciente e co-consciente. Ele possibilita aos seres humanos - vinculados em constelações afetivas mediante a operação constante das funções pensar-perceber e intuir-sentir de cada um - o 'conhecimento' da situação real de cada indivíduo e dos outros na matriz relacional de um grupo (p. 207).

Para Gonçalves et al. (1988), "na vida real, em sociedade, os indivíduos têm funções determinadas por circunstâncias sócio-econômicas, por sua 
inserção em uma determinada classe social, por seu átomo social e por sua rede sociométrica" (p. 66). Dessa forma, as pessoas desempenham então diversos papéis: profissionais, determinados pela classe social, afetivos, familiares entre outros. De acordo com Moreno, os papéis são observáveis e mensuráveis, sendo o conceito de papel mais apropriado do que de personalidade.

Na perspectiva de Moreno (2008), dentro de um sistema sociométrico podemos identificar três processos: a realidade aparente de uma sociedade, a realidade interna da matriz sociométrica e a realidade social, ou seja, os agrupamentos sociais dinâmicos historicamente crescentes que constituem o universo social concreto.

Para Gonçalves et al. (1988), na teoria psicodramática, as redes sociométricas são compostas por diversos átomos sociais, ou seja, a configuração social das relações interpessoais que se desenvolvem a partir do nascimento, inicialmente na relação mãe e filho e que vai se estendendo a outras pessoas que entram no círculo da criança e assim sucessivamente por toda a sua vida. Trata-se de um processo que está permanentemente em transformação. As redes sociométricas configuram-se por vários átomos sociais, nem sempre evidentes. Uma pessoa ao relacionar-se, não necessariamente irá se relacionar com todas as pessoas que formam o átomo social do outro. Ela irá se relacionar com pessoas que tem afinidades, que estabelece uma tele. Mediante o mapeamento de uma rede é possível entender como essas relações se configuram e influenciam os seus atores. As redes são fenômenos objetivamente observáveis, apesar de decorrerem também de variáveis subjetivas e de representações de papéis.

Para Bustos (1979),

As redes sociométricas se configuram a partir do entrelaçamento dos vínculos. Assim, cada pessoa se movimenta dentro de um átomo social: conjunto de vínculos próximos que constituem a rede de relação de um indivíduo. Uma pessoa sociometricamente isolada costuma ter um átomo social pobre, fixado nas figuras que constituem sua 'matriz de identidade' primária. A matriz de identidade é o conjunto de vínculos nos quais a pessoa se insere ao nascer (p. 20).

As redes sociais mediadas pelo computador são redes sociométricas virtuais, e dependendo do uso que as pessoas fazem da rede, ela cria redes de afinidades pela tele, formando novos átomos sociais e culturais.

\section{Redes Comunitárias, Comunidades Virtuais, Ciberespaço e Cibercultura}

Conforme Montero (2008), as redes comunitárias podem ser definidas como:

Conjunto de relações complexas de trocas entre múltiplos e diversos atores, com variados estilos de ação, que mantêm um fluxo e refluxo constante de informações e mediações organizadas e estabelecidas em prol de um fim comum: o desenvolvimento, fortalecimento e cumprimento de metas específicas de uma comunidade em um contexto particular (p. 294, tradução nossa).

Para Freitas e Montero (2006), a ideia da sociedade como um tecido em que se entrelaçam as vidas e as ações é muito antiga. É frequente a presença de redes em diferentes contextos e campos profissionais que vão desde a informática até as ciências sociais. "As redes são uma forma de organização social no qual se produz um intercâmbio contínuo de ideias, serviços, objetos e modos de viver (p. 173). "As redes são a expressão mais evidente das relações sociais que construímos e também o que somos" (p. 177), uma estrutura social em que as pessoas e a sociedade encontram apoio, abrigo e recursos. As redes sociais podem se consideradas como um caminho para o desenvolvimento da cidadania. A relação social é o que caracteriza as redes e elas acontecem por meio de parentesco, informação, troca de bens e serviços, entre outros. Além de ser uma fonte criativa de recursos, dinâmica e flexível, denota-se extremamente complexa como todo fenômeno humano. Segundo as autoras, o estudo das redes comunitárias é uma possibilidade de ver as atividades das comunidades que supõe um tipo de organização complexa tanto no nível social como local. Os processos organizativos na comunidade não envolvem necessariamente todos os seus membros:

É difícil separar a definição de rede das funções a que se propõe, pois parecem ser formas de agrupação social que se estruturam em torno de uma finalidade... Alguns grupos dentro da rede

Psicol. Argum. 2014, 32(79), Supl. 2, 99-109 
podem ter uma maior identificação entre si e por isso mantêm relações mais intensas e frequentes sem que isso afete a dinâmica da rede. Nesta mesma ordem de ideias, é comum a presença de várias redes menores dentro da mais ampla, em que cada membro desta pode pertencer a outras redes, e em um dado momento poderá vincular-se com objetivos, estratégias e metas da rede maior (pp.188-190, tradução nossa).

Itriago e Itriago (2000, citado por Freitas e Montero, 2006) assinalam alguns aspectos essenciais de uma rede: elas devem ser independentes de setores governamentais e empresariais; devem ser representativas no sentido de responder aos interesses que pretendem apoiar; ser participativas, ou seja, todos os membros devem ter a possibilidade de intervir para alcançar os objetivos; não pressupõem uma hierarquia e a organização deverá ser horizontal; proteger e propagar valores sem colocá-los como uma imposição; ser ativas e interativas, pois a rede é uma estrutura dinâmica em relação a outras estruturas semelhantes; ser estáveis, portanto, deverão ter alguma permanência; ser transparentes: suas atividades e motivações devem ser conhecidas e explícitas; ser flexíveis, para adaptar-se e responder as circunstâncias do ambiente e suas demandas; não visar lucro, os seus objetivos não são individuais e sim da comunidade, e principalmente, estar em sintonia com a comunidade.

Segundo Freitas e Montero (2006), as redes comunitárias possuem algumas características que se apresentam de forma particular em cada rede comunitária. Sua estrutura e funcionamento acontecem em função da história, da localização e dos atores envolvidos na comunidade. As características propostas pelas autoras são as seguintes: pluralidade e diversidade dos membros; multimodalidade e multidimensionalidade da intervenção; inter-relação de todos os membros; dinâmica das relações; construção coletiva; interdependência; participação e compromisso; diversidade e particularidade; pontos de tensão e de negociação; construção e reconstrução; troca de experiências; formação e serviços; cogestão; democratização de conhecimentos e poder compartilhado; afetividade, filiação e solidariedade e flexibilidade.

Freitas e Montero (2006) apresentam uma classificação das redes comunitárias em que utilizam alguns critérios para definição dos tipos e, ainda, lembram que estes diferentes tipos não são excludentes. 0 primeiro critério diz respeito aos atores envolvidos no processo (as redes podem ser classificadas em interpessoais, inter-grupais, interinstitucionais e combinadas); o segundo critério é definido de acordo com o âmbito que envolve as redes (intracomunitárias e intercomunitárias); o terceiro aspecto dá-se de acordo com o funcionamento (podem ser circunstanciais ou estáveis); outro aspecto em função do reconhecimento (visíveis ou invisíveis) e conforme a sua estrutura (podem ser espontâneas, estruturadas ou institucionalizadas).

Para Freitas e Montero (2006), alguns processos psicossociais são obstáculos e desvirtuam o processo das redes comunitárias, como líderes autossuficientes e egocêntricos, desconfiança entre os membros, lutas de poder, desesperança e a rigidez do pensamento organizativo.

A psicologia Social Comunitária tem estudado os processos que permitem a formação de redes e que podem fortalecer sua atividade. Conclui-se, de acordo com Freitas e Montero (2006), que alguns processos psicossociais podem fortalecer as atividades das redes comunitárias e apresentam muitas vantagens para a comunidade.

As redes comunitárias promovem a conexão de diferentes atores para realização de parcerias, fortalecendo projetos e ações sociais. As redes sociais mediadas pelo computador também podem ser uma ferramenta na qual é possível fazer intervenções utilizando-se de processos de concientização, desalienação e fortalecimento comunitário. Esse espaço antropológico no mundo virtual muitas vezes serve de palco para mobilizações sociais e protestos. A disseminação de informações pode ser muito rápida e atingir um grande número de pessoas, independente das demarcações geográficas.

Segundo Castells (2003), a tecnologia da informação é hoje o que a eletricidade foi na era industrial. A era da informação tem a internet como base tecnológica, formando o que se chama de rede. As redes podem ser compreendidas como um conjunto de nós interconectados, cuja formação é uma prática humana muito antiga, mas que ganharam na contemporaneidade nova vida, transformando-se em redes de informação promovidas pela internet. A internet é um meio que permite a comunicação de muitos com muitos, em uma escala global.

Dentro desta perspectiva, denota-se uma semelhança entre as redes sociais comunitárias e as 
redes virtuais, pois as comunidades no ciberespaço também se formam em função de afinidades e interesses comuns. Na sociedade contemporânea as relações estão mais fluídas e o desenvolvimento da tecnologia permitiu a ampliação do espaço real para o mundo virtual, rompendo as barreiras territoriais.

A relação por meio das chamadas comunidades virtuais mudou significativamente a forma como as pessoas se relacionam e interagem. É importante buscar a compreensão das possíveis consequências que poderão acontecer com o uso desta ferramenta de comunicação.

Conforme Arendt (1998):

Na contemporaneidade, emergem situações, acontecimentos, acelerações que criam novas formas sociais, novas instituições, novas formas de identidade e de relações recíprocas associadas a novos modelos de sensibilidade. [...] o psicólogo comunitário cria seu objeto, acredita em sua estabilidade, supõe a comunidade enquanto espaço identitário, relacional, histórico, no qual cada membro é representativo da totalidade local (pp. 3-4).

Segundo Lévy (1996), "a palavra virtual vem do latim medieval virtualis, derivado por sua vez de virtus, força, potência. Na filosofia ecoclástica, é virtual o que existe em potência e não em ato" (p. 15). Uma comunidade virtual pode organizar-se sobre uma base de afinidades por intermédio de sistemas de comunicação telemáticos: seus membros estão reunidos pelos mesmos núcleos de interesses e problemas e, ainda que não seja presencial, essa comunidade está repleta de paixões, projetos, conflitos e amizades.

Na concepção de Lemos (2004), por meio de uma conectividade telemática, o ciberespaço caracteriza-se pela formação de uma sociedade estruturada, ampliando o seu potencial comunicativo, proporcionando a troca de informações sob as mais diversas formas, promovendo agregações sociais e produzindo informação. A cibercultura forma-se da convergência entre o social e o tecnológico. "Mais do que um fenômeno técnico, o ciberespaço é um fenômeno social" (p. 138).

Lévy (1999) define o ciberespaço como "espaço de comunicação aberto pela interconexão mundial dos computadores e das memórias dos computadores” (p. 92). Quanto à cibercultura: "[...] conjunto de técnicas (materiais e intelectuais), de práticas, de atitudes, de modos de pensamento e de valores que se desenvolvem juntamente com o crescimento do ciberespaço" (p. 17).

Tanto nas comunidades off-line quanto on-line, as pessoas compartilham ideias em torno de interesses comuns e buscam o reconhecimento do grupo, e a psicologia tem um papel fundamental na compreensão desses processos.

Para Ornelas (2008):

O conceito de sentimento de comunidade e as formas pelas quais as comunidades satisfazem as necessidades de pertença dos seus membros tem sido uma das áreas de investigação privilegiadas no campo da psicologia comunitária. [...] nestes contextos formais e informais, as pessoas podem encontrar recursos materiais, desenvolver afinidades pessoais e sentimentos de identidade, de integração e de comunidade, através das suas ligações com os outros (pp. 39-40).

De acordo com Montero (2008), a psicologia comunitária dá grande ênfase na noção de território, no entanto, apenas compartilhar um espaço, um lugar, não denota uma comunidade. A autora, ao falar das comunidades virtuais, questiona como estas comunidades têm sido entendidas pela psicologia comunitária e se os conceitos e métodos deste campo são adequados para trabalhar com estes grupos:

Não tentarei responder aqui essas perguntas, pois creio que se trata de um tema que merece um espaço a parte de investigação do campo virtual e "real" (esta afirmação é uma demarcação). Tenho recebido respostas exclamativamente negativas de pessoas que estudam os processos psicossociais cibernéticos. E há certos aspectos que devem ser examinados: como se sabe quem é a pessoa com quem se conversa através da internet? Como se verifica a veracidade dos dados de identificação (as descrições pessoais, por exemplo)? Será que isso importa? 0 que acontece quando alguém sai da rede ou é retirado da lista? Isso afeta o grupo? Como? Quando alguém é muito participativo e não recebe resposta, o que isso significa? Como fazer esta leitura? (pp. 203-204, tradução nossa).

O Brasil foi o país que mais cresceu no Facebook em 2012, com quase 30 milhões de novos usuários ativos mensais, e atualmente é o segundo país com

Psicol. Argum. 2014, 32(79), Supl. 2, 99-109 
maior número de usuários (65 milhões), atrás apenas dos Estados Unidos (167 milhões) (Socialbakers, 2013). De acordo com os números, percebe-se que esse dispositivo tecnológico passou a fazer parte do dia a dia de muitas pessoas, por isso, a importância desta reflexão sobre o seu uso. A seguir, servindo-se de dados de algumas pesquisas, faremos uma breve explanação sobre o conceito de capital social relacionado ao uso do Facebook.

\section{Algumas Pesquisas com Usuários do Facebook}

Burke, Marlow e Lento (2010) realizaram uma pesquisa com 1193 usuários do Facebook que utilizassem essa rede social por no mínimo dois meses e que falassem língua inglesa. Recrutaram os participantes em um anúncio dentro do próprio Facebook e aplicaram um questionário, além da observação da página dos participantes. Os objetivos da pesquisa foram validar uma escala de autoavaliação sobre o uso do Facebook, testar se os achados das pesquisas anteriores que foram realizadas com estudantes universitários se aplicam em populações mais velhas e internacionais e investigar as atividades específicas ligadas à sensação de capital social e solidão. Em particular foi investigado o papel da interação dirigida entre pares (postagens, comentários, curtir) e o consumo de conteúdo de amigos, incluindo atualização de status, fotos e conversa de amigos com outros amigos. Consumo na visão dos autores quer dizer o monitoramento de todo conteúdo que não é dirigido especificamente a um determinado usuário (publicações gerais), e sim para grandes audiências, como, por exemplo, atualizações de status ou apenas olhar a conversa entre amigos.

Burke, Kraut e Marlow (2011) referem-se ao capital social como os recursos potenciais ou reais que estão conectados a uma rede durável de relacionamentos mais ou menos institucionalizados de mútuo conhecimento e reconhecimento. É o benefício que vêm da posição de uma pessoa em uma rede social, o número e o tipo de relações que essa pessoa mantém e os recursos que as conexões em si possuem. Capital social é frequentemente descrito como sendo de dois constructos: de ligação, ou seja, em relacionamentos próximos emocionalmente, tais como membros da família e bons amigos que permite reciprocidade específica, suporte emocional e companheirismo. Por outro lado, um grande número de ligações mais fracas e diversificadas que atravessam diferentes círculos gera o capital social de construção. 0 capital social de construção dá acesso a novas informações, como, por exemplo, oportunidades de emprego, porque as ligações mais próximas e mais fortes terão provavelmente muita informação redundante. Os estudos revelaram que o recebimento de mensagens de amigos é associado ao capital social voltado para a construção de novas conexões, mas que outros usos não (não aumentam o capital social), ao mesmo tempo usar o site para consumir notícias passivamente ajuda aquele com menor fluência social a extrair mais valor de suas conexões. Novos conhecidos nos expõem a perspectivas diversificadas e grupos externos, mas não necessariamente oferecem suporte emocional. O capital social de ligação e de construção não são mutuamente excludentes; na verdade são diferentes dimensões dos recursos de uma rede social. Dos três tipos de engajamento social das atividades em uma rede social, (comunicação direta, consumo de notícias e envio de mensagens não direcionadas) apenas as interações direcionadas pessoa a pessoa mostraram estar associadas ao aumento do capital social de construção. Somente a comunicação direta permite aumentar o capital de construção, o consumo passivo e o envio de mensagens não direcionadas não desenvolvem relacionamentos e não permitem que as pessoas interajam entre si para buscar ajuda mútua. Os usuários com menor capacidade de comunicação se beneficiam mais do Facebook na questão do capital social de construção.

Burke et al. (2010) concluíram que a comunicação direta é associada a maiores sentimentos de capital social de ligação e menor solidão e tem uma relação modesta com a construção de capital social, que é primariamente relacionada com o tamanho da rede de amigos. Usuários que acessam maior volume de conteúdo (consumo) na rede social relatam uma redução no capital social e maior solidão. Os autores ainda concluem que as pessoas se sentem mais conectadas socialmente quando gravitam em direção a sistemas técnicos que confirmam essas conexões. 0 uso de sites como o Facebook permite reforçar relacionamentos distantes ou recentes e há um feedback positivo quanto mais se utiliza a ferramenta. Esses achados podem ser generalizados para populações mais velhas e para pessoas que falam inglês fora dos EUA. Os resultados não falam de causalidade, contudo, os pesquisadores esperam 
repetir a coleta de dados mais duas vezes, com intervalos de seis meses com os mesmos participantes para observar o potencial de relação social causal entre o uso de redes sociais e o "bem estar social":

A comunicação direta tem o papel esperado no capital social de ligação. Mensagens trocadas entre amigos são tanto um produto da amizade quanto um meio de facilitar e manter tais amizades. No entanto, os resultados para o consumo de conteúdo são de certa forma surpreendentes, pois ao acompanhar as comunicações diretas, os usuários que clicam em muitas histórias sobre seus amigos reportam um capital social de construção reduzido. Uma interpretação seria que, para colher os benefícios de uma rede diversificada, é preciso tanto ter um conjunto de conexões fracas diversificadas quanto ter o contexto de comunicação para se beneficiar delas. Os resultados são menos surpreendentes para a solidão. Pessoas que sentem uma discrepância entre as interações sociais que tem e as que desejariam ter tendem a passar mais tempo observando as interações de outras pessoas. Se é a solidão que causa os clics, ou se são os clics que causam a solidão é algo a ser visto em futuras ondas deste estudo (p. 9, tradução nossa).

Burke et al. (2011) descrevem uma pesquisa realizada com 415 usuários do Facebook, os mesmos participantes da pesquisa citada anteriormente (Burke et al., 2010), com o objetivo de verificar como esse uso afeta o capital social dependendo de: 1. Tipos de atividades no site contrastando atividades de comunicação um a um e envio de mensagens para grandes audiências e consumo passivo de notícias sociais; 2. Diferenças individuais entre usuários incluindo capacidade de comunicação social e autoestima. 0 estudo apresenta evidências conclusivas da necessidade de diferenciar usos e usuários em estudos de mídias sociais, pois nem todo o tempo é igualmente social mesmo em plataformas inerentemente sociais. 0 tempo gasto por indivíduo pode variar bastante. Conclui-se que receber mensagens, mas não enviar mensagens, está ligado a um aumento do capital social de construção; além disso, alguns efeitos dependem da pessoa. 0 consumo passivo de conteúdo de amigos não tem nenhum efeito em usuários com habilidades sociais acima da média, mas ajuda aqueles que têm dificuldade de se comunicar pessoalmente, permitindo que se beneficiem de recursos que os seus relacionamentos possam colocar a sua disposição. A autoestima não influencia na forma como as pessoas interagem nas redes sociais.

Sum, Mathews, Pourghasem e Hughes (2008), da Universidade de Sidney, realizaram uma pesquisa on-line com 222 pessoas com idade superior a 55 anos. No questionário haviam perguntas relacionadas ao uso da internet, capital social e bem-estar. Os respondentes relataram usar a internet para várias finalidades, como busca de informação, entretenimento, compras pela internet (comércio eletrônico), comunicação e para conhecer novas pessoas. 0 uso da internet permite que os usuários mais velhos se socializem sem restrição de fronteiras, mobilidade ou restrições físicas. Os resultados do estudo revelaram que o uso da internet diminui a solidão quando usada para busca de informações e comunicação, porém quando os adultos tentam utilizar a internet para conhecer novas pessoas, parecem sentir-se ainda mais solitários. Os usuários nesta faixa etária que mais tiram proveito do uso da internet são os que utilizam essa tecnologia para apoiar as amizades já existentes.

\section{Considerações Finais}

O Facebook é uma plataforma de comunicação on-line mediada pelo computador e caracterizada como rede social que funciona por meio de perfis e comunidades. 0 site possibilita o contato entre seus atores utilizando-se de interações que podem ser lúdicas, profissionais, políticas e de cidadania. No Brasil, as redes sociais tem modificado os hábitos culturais dos brasileiros e ganham novos adeptos a cada dia.

Esta modalidade de relacionamento virtual mudou significativamente a forma como as pessoas se relacionam e interagem. 0 presente estudo teve como finalidade analisar o ciberespaço como um fenômeno social, possibilitando uma reflexão sobre as redes virtuais.

Para o psicodrama, a identidade se forma na inter-relação, na internalização de papéis e na relação da pessoa com o mundo. Toda relação interpessoal acontece por intermédio dos papéis. A pessoa desenvolve diversos papéis ao mesmo tempo, que influenciam o ambiente e a cultura ao qual está inserido. A personalidade constitui-se na fusão de elementos

Psicol. Argum. 2014, 32(79), Supl. 2, 99-109 
coletivos e privados. Cada pessoa tem uma história única, particular, mas também agrega componentes do meio em que vive. É nesta relação dialética entre sujeito e meio que se forma a subjetividade.

As comunidades virtuais, mesmo não sendo presenciais, também são permeadas por interesses comuns, afinidades, paixões e conflitos. A rede poderá ir tão longe quanto o fator tele permitir. Podemos dizer que o fator tele, ou seja, a empatia em via dupla, é responsável pela coesão grupal. Trata-se de uma espécie de ligação entre as pessoas, um fenômeno que mantém o funcionamento e a coesão dos grupos. Nas redes virtuais as relações também acontecem desta forma, e as pessoas podem fazer suas escolhas de amizades a partir de três modos relacionais conforme a teoria psicodramática: atração (proximidade), rejeição (distância) e neutralidade. Uma característica importante no mundo virtual é que as redes podem ser mantidas pelo tempo, mesmo que os atores não tenham interação entre si.

Com o uso deste dispositivo tecnológico as pessoas podem fazer novas amizades (contatos) e também resgatar laços da infância, amorosos, de colégio, faculdade e profissionais. 0 espaço virtual torna-se um facilitador para ampliação e formação de novas redes.

Na visão moreniana, as redes sociométricas configuram-se a partir dos entrelaçamentos dos vínculos e são compostas por diversos átomos sociais, formando uma teia de sociabilidades. No mundo virtual, essas comunidades podem criar redes de afinidades por intermédio do fator tele, formando novos átomos sociais e culturais. Por meio do mapeamento de uma rede, seja ela virtual ou presencial, é possível entender como essas relações se estabelecem e influenciam seus atores. 0 sujeito e o meio (cenário) estão em constante transformação em função dessa relação.

A maneira como a pessoa utiliza este dispositivo tecnológico e estabelece suas relações no ambiente virtual terá um impacto em seu capital social. 0 capital social pode ser de ligação e de construção. Em meio a elos fortes e fracos é possível ter relacionamentos próximos obtendo suporte emocional e também ligações mais fracas e diversificadas que possam gerar apenas informações. 0 capital social de ligação e de construção não são mutuamente excludentes e os atores sociais podem fazer diferentes usos das redes sociais beneficiando-se delas ou não.
O Facebook tem um grande impacto tanto social como político. As redes virtuais muitas vezes são utilizadas como "espaços" de protestos, sendo também um facilitador das mobilizações sociais, já que as informações acabam se dissipando de uma forma extremamente rápida e para muitas pessoas ao mesmo tempo.

Finalizando, trazemos a contribuição de Silva (2001) ao colocar que a internet denota-se simultaneamente real e virtual (representacional). "O espaço e o tempo na rede existem na medida em que são construções sociais partilhadas. Esta construção é estruturada pelos laços e valores sociopolíticos, estéticos e éticos que tipificam este novo espaço antropológico" (p. 151). O espaço vem a ser um suporte aos processos cognitivos, sociais e afetivos. As pessoas constroem suas identidades e seus laços sociais, gerando uma teia de novas sociabilidades que suscitam novos valores e estes reforçam novas sociabilidades. Esta dialética torna-se facilitadora de novas práticas culturais.

Esta pesquisa não tem a pretensão de esgotar o assunto. Trata-se de uma reflexão sobre essa nova forma de relacionamento que acontece através das redes virtuais. Os dados sugerem a importância de realizar mais pesquisas para compreender como as redes sociais podem influenciar na construção da subjetividade, quais valores poderão ser suscitados a partir desta prática, verificar possíveis influências e consequências do uso desta ferramenta na sociabilidade contemporânea e analisar como acontecem os processos de fortalecimento comunitário, conscientização e sentimento de pertença.

\section{Referências}

Arendt, R. J. J. (1998). Psicologia social, comunidade e contemporaneidade. Psicologia, Reflexão e Crítica, 11(1), 135-145. Recuperado em 23 de novembro de 2010, de http://www.scielo.br/scielo.php?script=sci_arttext\&p id=S0102-79721998000100008

Burke, M., Marlow, C, \& Lento T. (2010). Social network activity and social well-being. Recuperado em 14 de julho de 2012, de http://www.cameronmarlow.com/media/burke-2010-social-well-being.pdf

Burke, M., Kraut, R., \& Marlow, C. (2011). Social capital on Facebook: Differentiating uses and users. Recuperado em 14 de julho de 2012, de http://www.cs.cmu. edu/ wcohen/10-802/burkeCHI2011.pdf 
Bustos D. M. (1979). O teste sociométrico, fundamentos, técnicas e aplicações. São Paulo: Brasiliense.

Castells, M. (2003). A galáxia da internet: Reflexões sobre a internet, os negócios e a sociedade. Rio de Janeiro: Jorge Zahar. (Obra original publicada em 2001).

Facebook (2012). Glossário do Facebook. Recuperado em 3 de setembro de 2012, de http://www.facebook.com/ help/glossary

Freitas, M. G., \& Montero, M. (2006). Las redes comunitárias. In M. Montero. Teoría y práctica de la psicologia comunitária: La tensión entre comunidad y sociedad. (pp.173-201). Buenos Aires: Paidós.

Fonseca, C. A. M. (2010). Cartografias do self no Facebook. Dissertação de Mestrado, Universidade de Coimbra, Coimbra, Portugal. Recuperado em 3 de agosto de 2012, de https://estudogeral.sib.uc.pt/bitstream/10316/14375/1/Tese\%20Alexandre\%20Final. pdf

Fonseca Filho, J. S. (1980). Psicodrama da loucura: Correlações entre Buber e Moreno. São Paulo: Ágora.

Gonçalves, C. S., Wolf, R. W., \& Almeida W. C. (1988). Lições de psicodrama: Introdução ao pensamento de J. L. Moreno. (10a ed.). São Paulo: Ágora.

Kirkpatrick, D. (2011). O efeito Facebook. Os bastidores da história da empresa que conecta o mundo. Rio de Janeiro: Intrínseca.

Lemos, A. (2004). Cibercultura, tecnologia e vida social na cultura contemporânea. (2a ed.). Porto Alegre: Sulina.

Lévy, P. (1996). O que é o virtual. (1a ed., P. Neves, trad.). São Paulo: 34 .

Lévy P. (1999). Cibercultura. (1a ed., C. I. da Costa, trad.). São Paulo: 34.
Miller, D. (2011). Tales from Facebook. Cambridge: Polity Press.

Menegazzo, C. M., Tomasini, M. A., \& Zuretti, M. M. (1995). Dicionário de psicodrama e sociodrama. São Paulo: Ágora.

Moreno, J. L. (1999). Psicoterapia de grupo e psicodrama. (3a ed., J. C. V. Gomes, trad.). Campinas: Livro Pleno.

Moreno, J. L. (2008). Quem sobreviverá? Fundamentos da sociometria, psicoterapia de grupo e sociodrama. Edição do Estudante. (M. Aguiar, trad.). São Paulo: Daimon Centro de Estudos do Relacionamento.

Montero, M. (2008). Introducción a la psicología comunitaria: Desarrollo, conceptos y procesos. Buenos Aires: Paidós.

Ornelas J. (2008). Valores fundamentais da psicologia comunitária. In J. Ornelas, Psicologia comunitária (pp. 3845). Lisboa: Fim de Século.

Recuero, R. (2010). Redes sociais na internet. Porto Alegre: Sulina.

Silva, L. J. O. L. (2001). A internet: A geração de um novo espaço antropológico. In A. Lemos \& M. Palacios (orgs.), As janelas do ciberespaço comunicação e cibercultura. (pp. 151-171). Porto Alegre: Sulina.

Socialbakers (2013). Facebook statistics by country. Recuperado em 17 de janeiro de 2013, de http://www. socialbakers.com/facebook-statistics

Sum, S., Mathews, M. R., Pourghasem, M., \& Hughes, I. (2008). Internet technology and social capital: How the internet affects senior's social capital and wellbeing. Journal of Computer-Mediated Communication, 24(1), 202-220. Recuperado em 10 de fevereiro de 2013, de http://onlinelibrary.wiley.com/ doi/10.1111/j.1083-6101.2008.01437.x/full

Psicol. Argum. 2014, 32(79), Supl. 2, 99-109 